\title{
Use of Supplementary Rotor Current Control in DFIG to Augment Fault Ride Through of Wind Farm as per Grid Requirement
}

\author{
K.E. Okedu ${ }^{1 *}$, S. M. Muyeen ${ }^{2}$, R. Takahashi ${ }^{1}$, and J. Tamura ${ }^{1}$ \\ ${ }^{1}$ Department of Electrical and Electronic Engineering, Kitami Institute of Technology, Japan \\ ${ }^{2}$ Department of Electrical Engineering, The Petroleum Institute, Abu Dhabi, U. A. E \\ *E-mail:kenokedu@yahoo.com
}

\begin{abstract}
Fixed speed wind turbine generator system that uses induction generator (IG) has the stability problem similar to the step-out phenomenon of a synchronous generator during grid fault. On the other hand, doubly fed induction generator (DFIG) can control its real and reactive powers independently while being operated in variable speed mode. This paper proposes a new control strategy using DFIGs for stabilizing wind farms composed of DFIGs and IGs, without incorporating additional FACTS devices. A new control scheme of limiting the rotor current of the DFIGs during grid fault was proposed. Simulation analysis by using PSCAD/EMTDC shows that the DFIGs can effectively stabilize the IGs and hence the entire wind farms through the proposed control scheme by providing sufficient reactive power to the system.
\end{abstract}

\section{INTRODUCTION}

The emerging grid codes demand that wind farms should have a good performance with respect to voltage control capability and robust behavior against frequency and voltage variations under fault condition [1]. The installations of compensation units, like static synchronous compensator (STATCOM) [2], superconducting magnetic energy storage (SMES) [3], and energy capacitor system (ECS) [4], in a wind farm composed of fixed speed wind turbines (FSWTs) to overcome low voltage ride through during a grid fault, increase the system overall cost. Therefore, it is paramount to use a variable speed wind turbine (VSWT) system like a DFIG to stabilize a FSWT (IG) in a wind farm, because the DFIG system can also control reactive power in a similar manner to a STATCOM, SMES, or ECS. Thus, the reactive power compensation can be implemented at a lower cost.

The doubly fed induction generator (DFIG) has very attractive characteristic as a wind generator because the power processed by the power converter is only a fraction of the total power rating of the DFIG. This is typically $20-30 \%$, and therefore its size, cost, and losses are much smaller compared to a full size power converter used in other variable speed wind generators [5]. DFIG can operate at a wide range of speed depending on the wind speed or other specific operation requirements. Thus, it allows a better capture of wind energy. The dynamic slip control and pitch control are the other salient features which help to augment the system stability. In addition, DFIG has better behavior concerning system stability during short-circuit faults in comparison with IG (Induction Generator), because of its capability of decoupling the control of active and reactive power output. The superior dynamic performance of the DFIG results from the frequency converter which typically operates with sampling and switching frequencies of above $2 \mathrm{kHz}$ [6]. At lower voltages down to $0 \%$ the IGBTs (Insulated Gate Bipolar Transistors) of the DFIG are switched off and the system remains in standby mode [7]. If the voltages are above a certain threshold value during/after fault, the DFIG system can be synchronized very quickly and back to normal operation [8].

However, during a grid fault, the frequency converter of the DFIG can be damaged due to large rotor currents generated [9], which causes to rise the DC-link voltage above nominal value. Therefore, crowbar switch, DC-link protective device, or other schemes should be considered to protect the frequency converter [10].

This paper presents a control scheme where IG is stabilized by using DFIG during a grid fault in a multimachine power system with wind farms connected. As the DFIG will be heavily stressed during the stabilization, a remedy should be found out to protect the frequency converter as well as to allow the independent control of real and reactive powers without losing the synchronism. The use of a crowbar is not recommended by the recent grid codes. A new control strategy to limit the rotor current within its nominal value during a grid fault is proposed in this work, in which the coordinating control of the d-q measured currents in the rotor side converter (RSC) of the DFIG and a DC chopper (braking resistor) protection scheme for the DFIG converters are included. The two-mass model was considered for all wind generators, as it has great influence on the transient stability feature. Simulations were run in PSCAD/EMTDC [11] for different fault conditions i.e., three line to ground, two line to ground, line to line, and one line to ground (3LG, 2LG, 2LS, 1LG) fault respectively to show the effectiveness of the DFIG control strategy employed. The transient stability index of the system is also analyzed for all 
fault conditions and for different fault locations in the power system to show the overall stability effect of DFIG to entire power system.

\section{MODEL SYSTEM}

A model system shown in Fig.1 [12] is considered in this study, where two wind farms are connected to the multimachine power system. Aggregated wind farm model is considered in this analysis for fast computing. Each wind farm is composed of 1 DFIG and 3 IGs. The wind turbine modeling, parameters of the generators, parameters of the DFIG excitation circuit and their configuration are given in [12-14].

The IEEE generic turbine model and approximate mechanical-hydraulic speed governing system [15] is used for synchronous generator 1 (SG1). The IEEE "non-elastic water column without surge tank" turbine model and "PID control including pilot and servo dynamics" speed-governing system [16] is used for synchronous generator 2 (SG2). IEEE alternator supplied rectifier excitation system (ACIA) [17] is used in the exciter model of both synchronous generators.

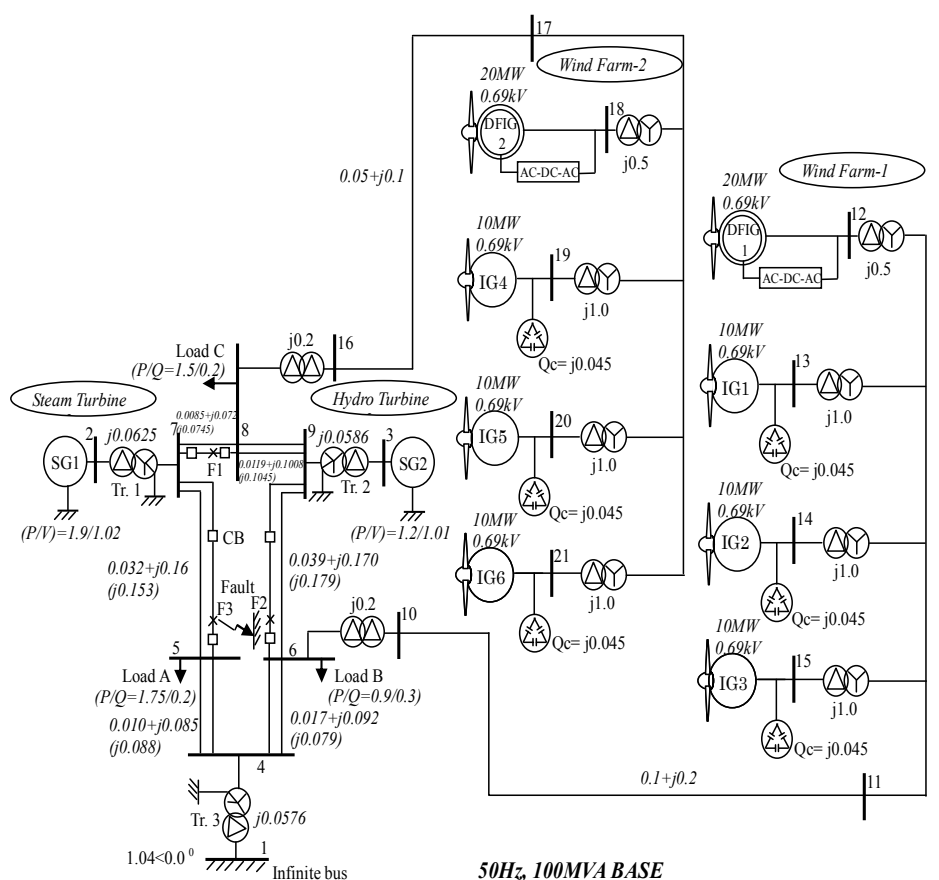

Fig. 1 Model system

\section{DFIG CONTROL}

The block diagram of the DFIG control systems, including the supplementary rotor current control during grid fault is shown in Fig. 2. The DFIG power converters are usually controlled based on the vector control technique. The DFIG control described below contains the electrical control of the power converters, which is essential for the DFIG behavior both in normal operation and during fault condition.

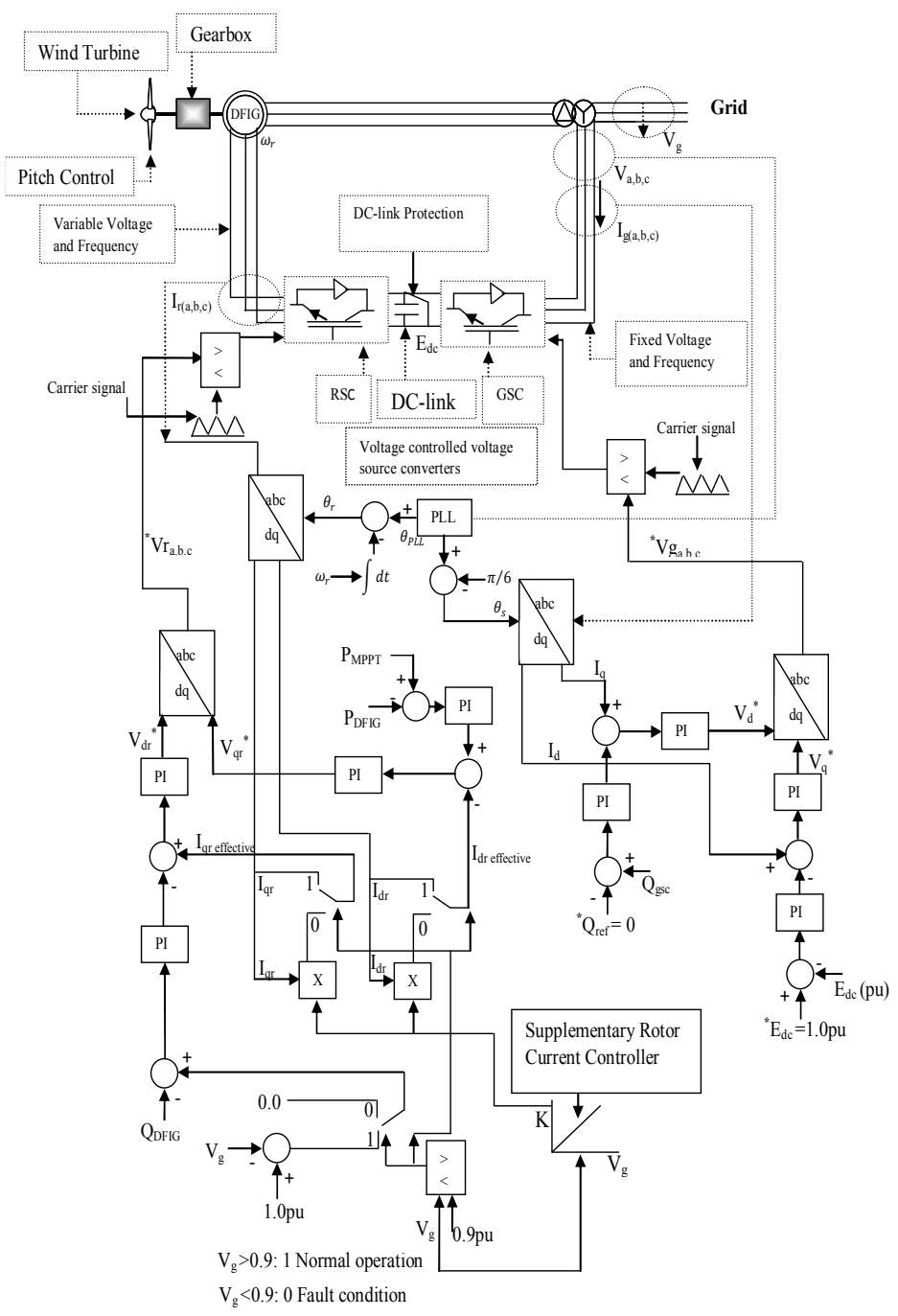

Fig. 2 Control block for DFIG

\section{A. Rotor side converter control}

In normal operation (when the grid voltage $V_{g}>0.9$ ), the RSC regulates the developed electric power $\left(P_{D F I G}\right)$ and delivers/absorbs reactive power as well by the DFIG. In Fig. 2, $\theta_{P L L}$ is the angle of the phase lock loop (PLL), and $\theta_{r}$ is the effective angle for the abc-dq0 and the dq0-abc transformations. The rotor side converter controls the terminal (grid) voltage to $1.0 \mathrm{pu}$. The d-axis current controls the active power, while the q-axis current controls the reactive power. After a dq0-to-abc transformation, $V_{d r}{ }^{*}$ and $V_{q r}{ }^{*}$ are sent to the PWM signal generator. Thus, ${ }^{*} \mathrm{Vr}_{\mathrm{abc}}$ is the three-phase voltage reference for the rotor side converter, that is obtained for the IGBTs switching as shown in Fig. 2.

A new control strategy was introduced in the RSC as shown in Fig. 2, whereby during normal operation the effective measured values of the d-axis and q-axis currents 
(Idr and Iqr) are same as that obtained directly from abc-to-dq transformation.

However, when a grid fault occurs, ie, $\mathrm{Vg}<0.9$, a comparator sends a signal to switch the measured currents $\mathrm{Idr}$ and Iqr to be multiplied by a variable $\mathrm{K}$ determined by the supplementary rotor current controller as shown in Fig. 2. The variable $\mathrm{K}$ is directly proportional to the magnitude of the grid voltage $\mathrm{Vg}$ during the grid fault; hence $\mathrm{K}$ takes different values for different grid disturbances like three lineto-grid fault (3LG), two line-to-ground fault (2LG), line-toline fault (2LS), and one line-to-ground fault (1LG).

The process of multiplying $\mathrm{K}$ to the measured $\mathrm{d}$ and $\mathrm{q}$ rotor currents during grid fault helps to limit the magnitude of the rotor current of the DFIG within its nominal value, and hence the use of expensive crowbar switch to disconnect the RSC from the DFIG during the grid fault can be avoided, since the recent grid codes require all wind turbine generators to remain connected to the power network during and after grid fault.

\section{B. Grid side converter control}

Fig. 2 also shows the control block for the GSC control, where PLL provides the angle $\theta_{P L L}$ and $\theta_{s}$ is the effective angle for the abc-to-dq0 (and dq0-to-abc) transformation. The GSC system of the DFIG is used to regulate the DC-link voltage $\left(E_{d c}\right)$ to $1.0 \mathrm{pu}$. The d-axis current controls the DClink voltage, while the q-axis current controls the reactive power of the grid side converter. After a dq0-to-abc transformation, $V_{q}{ }^{*}$ and $V_{d}{ }^{*}$ are sent to the PWM signal generator. Finally ${ }^{*} \mathrm{Vg}_{\mathrm{abc}}$ is obtained as a three phase voltage reference for the GSC output.

\section{GRID CODES}

The most worrying problem that wind farm must face is a voltage dip in the grid during a grid fault [18]. The magnitude of the voltage is controlled by the reactive power exchange. Fig. 3 displays the typical requirement for fault-ride through grid code. The wind farm must remain connected to the grid if the voltage drop is within the defined r.m.s. value and its duration is also within the defined period as shown in the curve [19]. Fig. 4 shows the rule of voltage support in the event of grid faults [19]

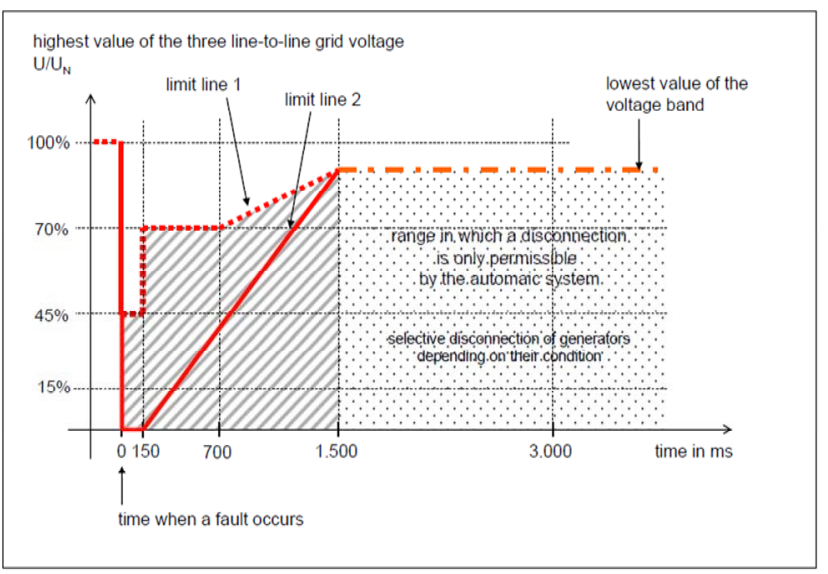

Fig.3 Fault ride through requirement for wind farm

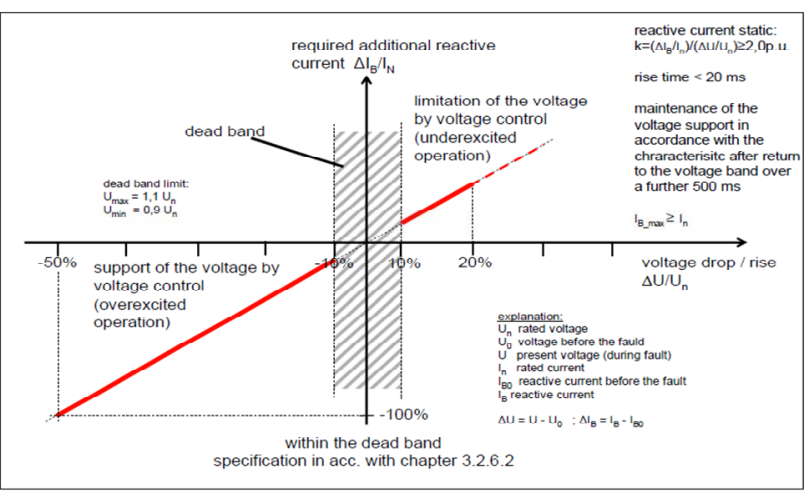

Fig. 4 The Rule of voltage support during grid fault as set by E.ON NETZ

\section{SimUlation RESUlts}

Simulation analyses on PSCAD/EMTDC for a three phase (3LG), two line-to-ground (2LG), two line-to-line (2LS) and one line-to-ground (1LG) faults at fault point F2 shown in Fig. 1 are performed for two cases to demonstrate the effectiveness of the control strategy, in which DFIG is installed or is replaced by IG at each wind farm. The fault occurs at $0.1 \mathrm{sec}$. The circuit breakers (CB) on the faulted lines are opened at $0.2 \mathrm{sec}$, and finally, at $1.0 \mathrm{sec}$, the circuit breakers are re-closed. The wind turbines are assumed to be operating in their rated wind speed during the various fault conditions. Responses of the network variables and some of the wind generators are shown in Figs. 5-19.

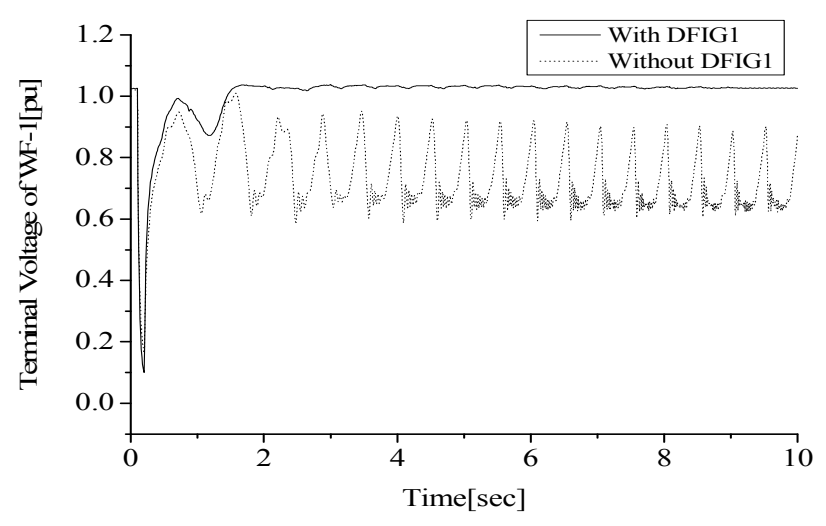

Fig. 5 Terminal voltage (Bus 11) of wind farm-1 (3LG)

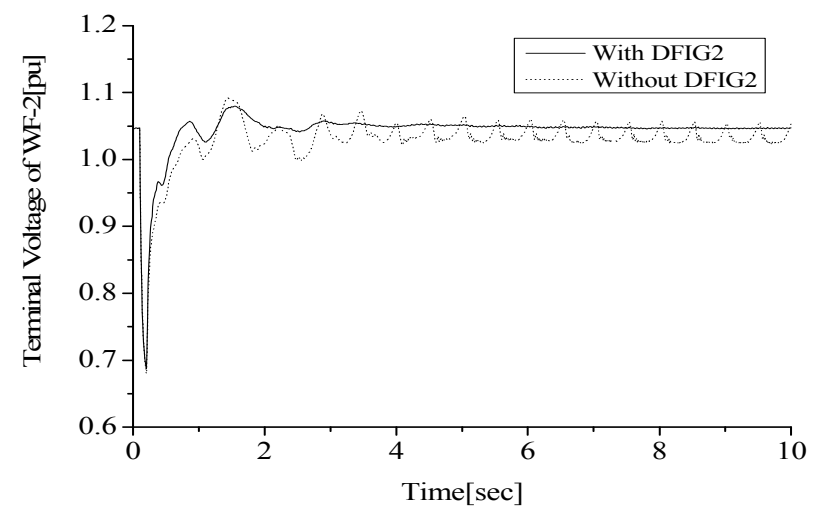

Fig. 6 Terminal voltage (Bus 17) of wind farm-2 (3LG) 


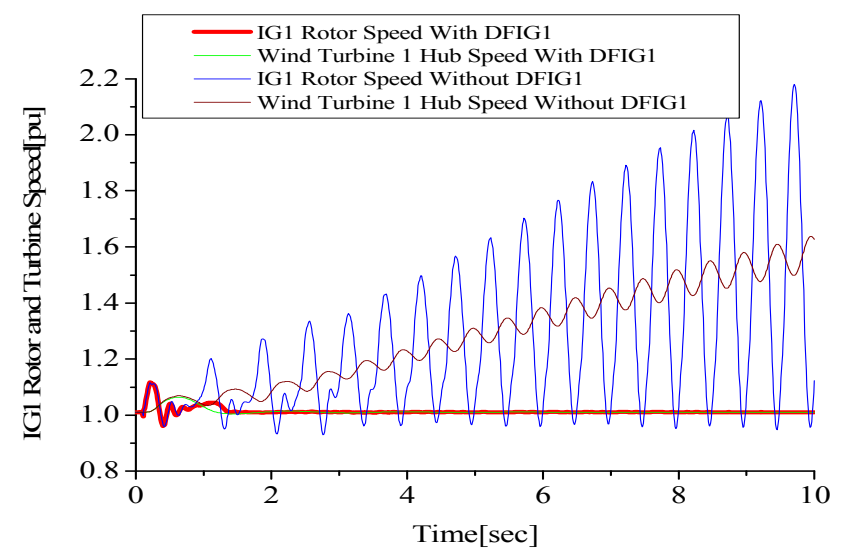

Fig. 7 IG-1 rotor and turbine hub speeds (3LG)

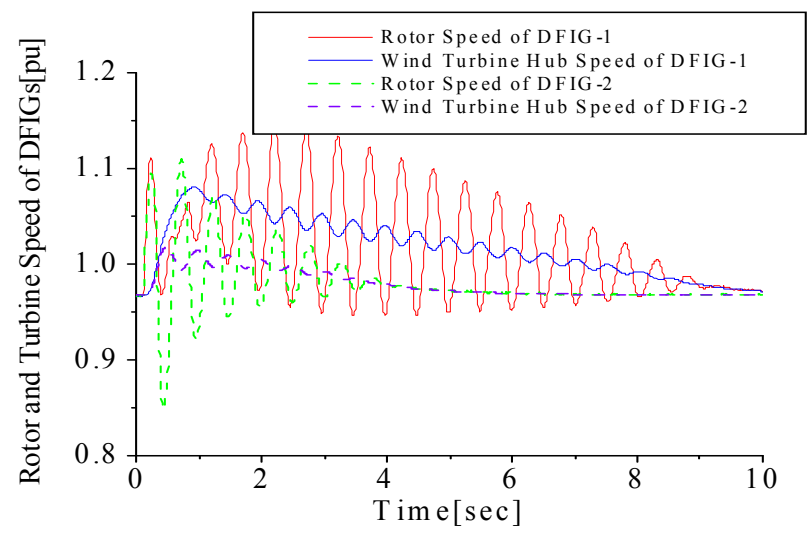

Fig. 8 DFIG-1 and DFIG-2 rotor and turbine hub speeds (3LG)

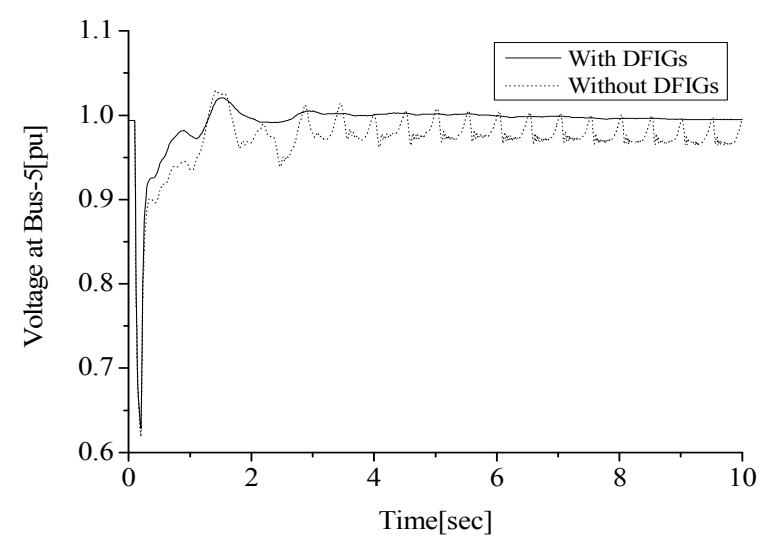

Fig. 9 Voltage at Bus 5 (3LG)

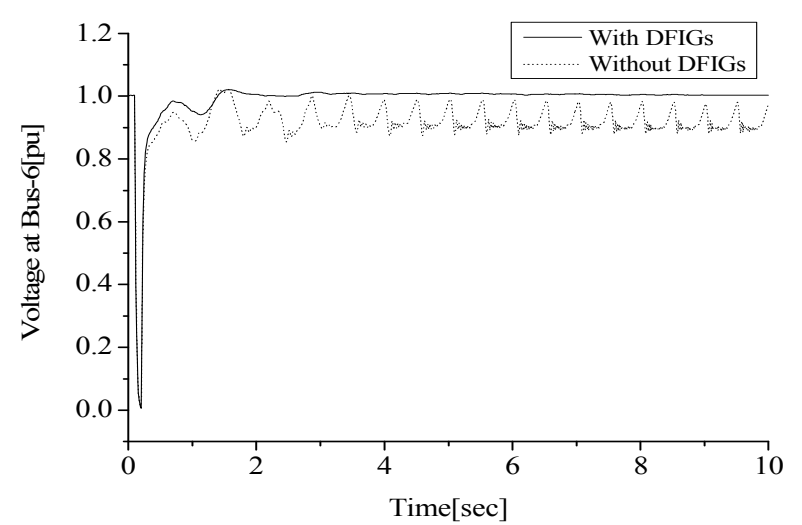

Fig. 10 Voltage at Bus 6 (3LG)

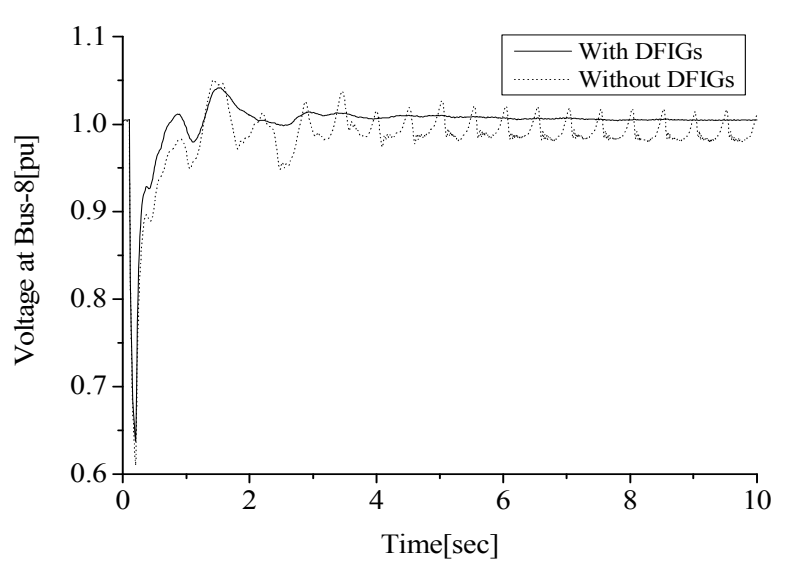

Fig. 11 Voltage at Bus 8 (3LG)

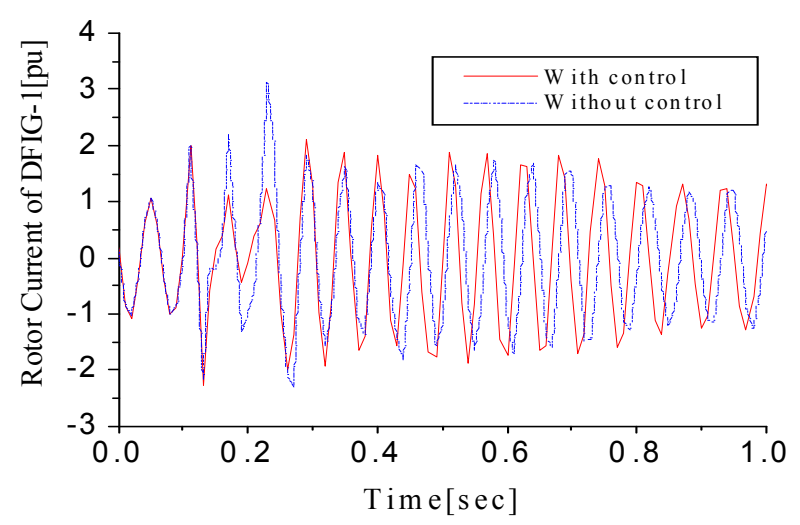

Fig. 12 Rotor current of DFIG-1 (3LG)

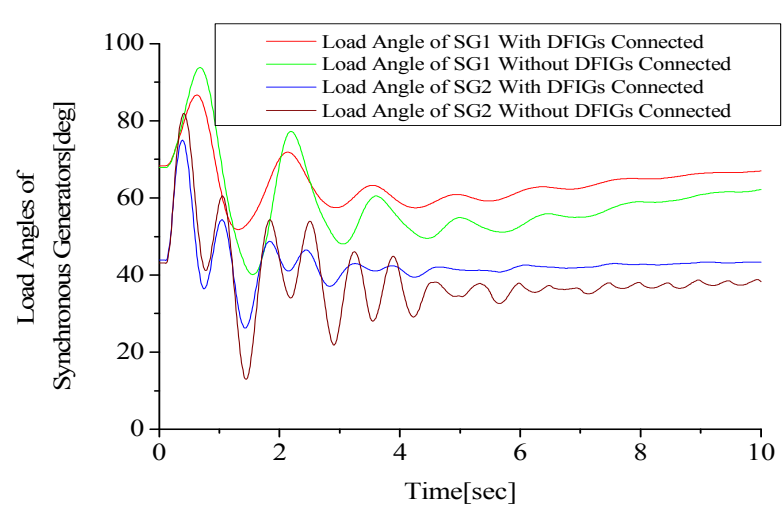

Fig. 13 Load angle of synchronous generators (3LG)

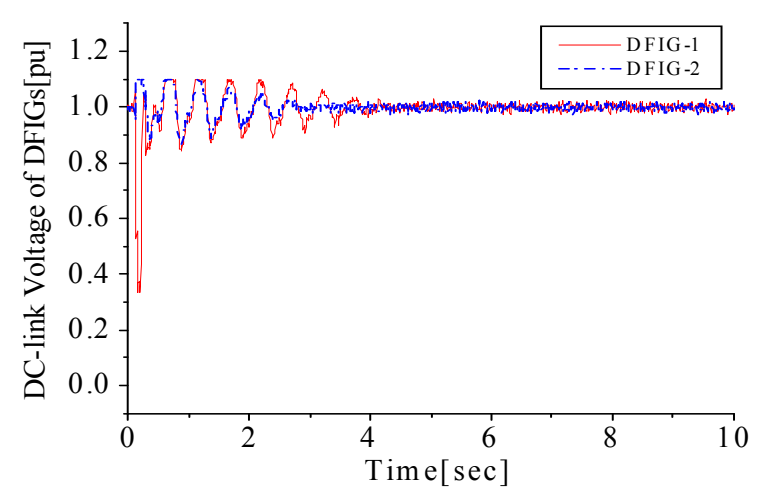

Fig. 14 DC link voltage of DFIG-1 and DFIG-2 (2LG) 


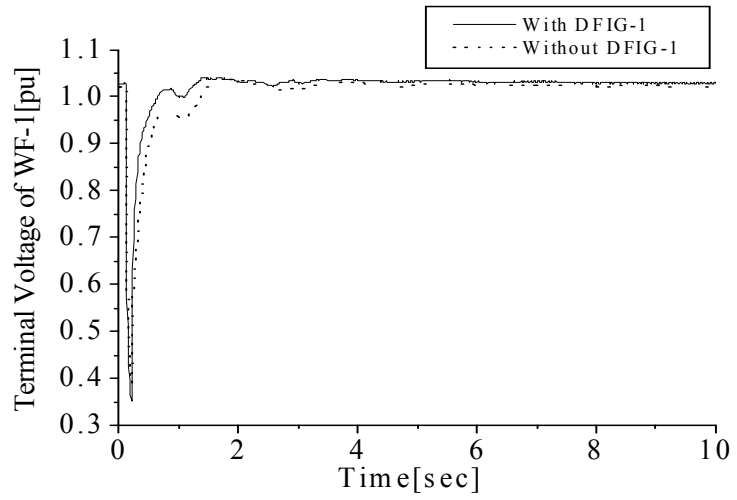

Fig. 15 Terminal voltage (Bus 11) of wind farm-1 (2LG)

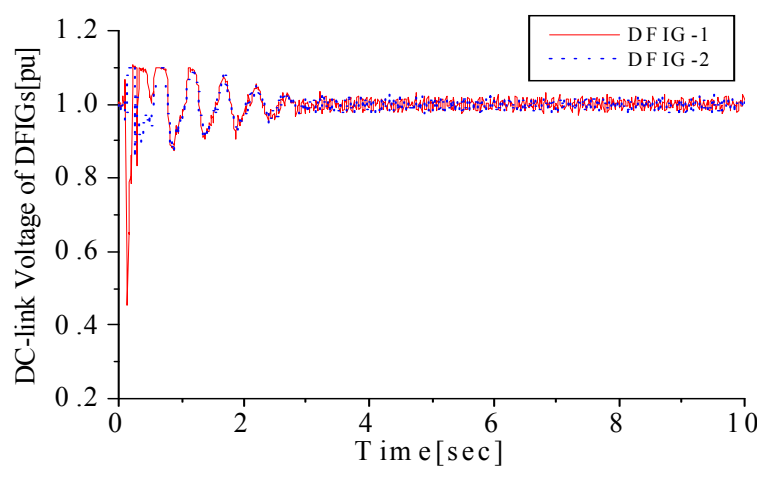

Fig. 16 DC link voltage of DFIG-1 and DFIG-2 (2LS)

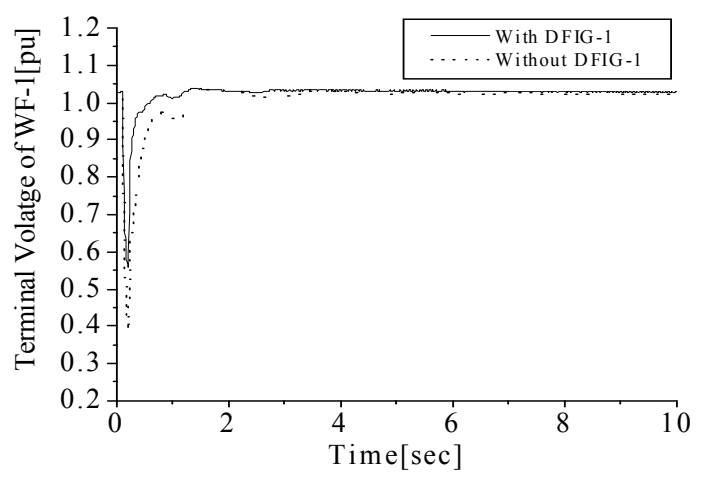

Fig. 17 Terminal voltage (Bus 11) of wind farm-1 (2LS)

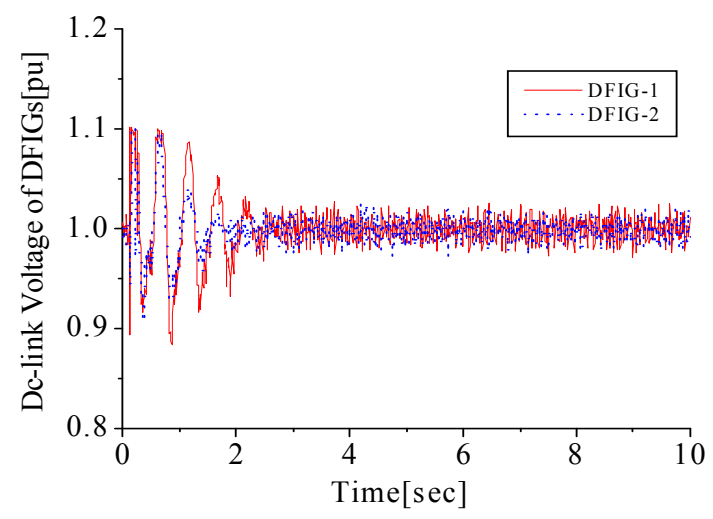

Fig. 18 DC link voltage of DFIG-1 and DFIG-2 (1LG)

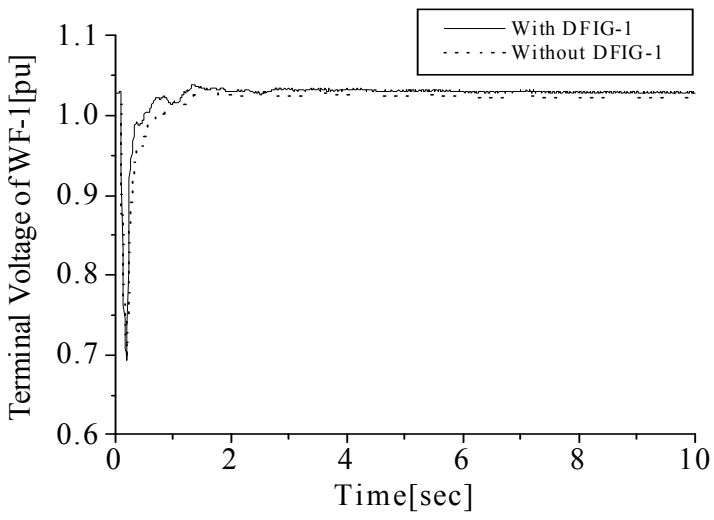

Fig. 19 Terminal voltage (Bus 11) of wind farm-1 (1LG)

The terminal voltage responses of wind farm 1 and 2 for the fault point $\mathrm{F} 2$ in Fig. 1 for a $3 \mathrm{LG}$ fault with and without considering DFIG control are shown in Figs. 5 and 6, respectively. When the DFIG control is not considered, the voltage drop occurs at the wind farm and also wind generator terminals. Then, the electromagnetic torques of the IGs drop also as the electromagnetic torque is proportional to the square of the terminal voltage. The mechanical torques of the wind turbines do not change rapidly during the short time interval. As a result, the turbine hub and generator rotors accelerate due to the large difference between the mechanical and electromagnetic torques, and then, the wind generators become unstable as shown in Fig. 7. But if the DFIG control is supplied, the necessary reactive power is supplied, and then, the terminal voltages of the wind farm and the electromagnetic torques of the IGs can be restored quickly making the wind generators stable. Fig. 8 shows the response of the DFIG rotor and wind turbine hub speeds, while Figs. 911 show the responses of the voltages at bus 5, 6 and 8. Fig. 12 shows the response of rotor current of DFIG-1, from which it can be observed that, when the control strategy of limiting the rotor current of the RSC of the DFIG is employed, the rotor current could be maintained within two times of its nominal value during the grid fault, though it is over three times of that value when no control was implemented. Fig. 13 shows the response of the load angles of SG-1 and SG-2. When the DFIGs are connected, better responses of the load angles are achieved.

The responses of the DC-link voltage of the DFIGs and the terminal voltage of wind farm- 1 for the two line-toground (2LG) fault are given in Figs. 14 and 15 respectively, while Figs. 16 and 17 shows the responses of the DC-link voltage of the DFIGs and the terminal voltage of wind farm-1 for the line-to-line fault (2LS). The responses of the DC-link voltage of the DFIGs and the terminal voltage of wind farm-1 for a line-to-ground (1LG) fault are shown in Figs. 18 and 19 respectively. 
VI. TRANSIENT StaBILITY EVALUATION OF THE SySTEM

The stability index, Wc, [20] defined as follows is used in evaluating the transient stability of the system:

$$
W(\mathrm{sec})=\int_{0}^{T} a b s\left(\frac{d}{d t} W_{\text {total }}\right) d t / \text { systembase power }
$$

Where $\mathrm{T}$ is the simulation time of $10.0 \mathrm{sec}$, and $\mathrm{W}_{\text {total }}$ is the total kinetic energy calculated by using the rotor speed of each synchronous generator as follows:

$$
\begin{aligned}
& W_{\text {total }}=\sum_{i=1}^{N} W_{i}(J) \\
& W_{i}=\frac{1}{2} J_{i} \omega_{m i}^{2}(J)
\end{aligned}
$$

Where $\mathrm{N}$ is the number of synchronous generators, and $J_{i}$ and $\omega_{i}$ denote inertia moment and rotor speed of each synchronous generator. The smaller the value of $\mathrm{W}_{\mathrm{c}}$, the better the system transient stability. The transient stability index against $1 \mathrm{LG}, 2 \mathrm{LS}, 2 \mathrm{LG}$, and $3 \mathrm{LG}$ faults with and without considering the DFIG control are shown in Table I, for the different fault points in the model system. From these results it can be understood that the proposed DFIG control can improve the transient stability of the entire power system.

TABLE III

TRANSIENT STABILITY INDEX [Wc(s)] OF THE SYSTEM

\begin{tabular}{|c|c|c|c|c|c|c|}
\hline & \multicolumn{2}{|c|}{$\begin{array}{c}\text { Without DFIG Control } \\
\text { (Fault Locations) }\end{array}$} & \multicolumn{3}{c|}{$\begin{array}{c}\text { With DFIG Control } \\
\text { (Fault Locations) }\end{array}$} \\
\hline Fault & F1 & F2 & F3 & F1 & F2 & F3 \\
\hline 3LG & 4.86 & 3.98 & 4.62 & 3.41 & 2.52 & 3.15 \\
\hline 2LG & 3.42 & 2.32 & 3.34 & 2.91 & 1.67 & 2.52 \\
\hline 2LS & 2.98 & 2.31 & 2.81 & 2.43 & 1.69 & 2.11 \\
\hline 1LG & 2.23 & 1.66 & 2.22 & 1.81 & 1.20 & 1.58 \\
\hline
\end{tabular}

\section{CONCLUSION}

A new control method for DFIG wind generators to stabilize a wind farm composed of both fixed speed and variable speed wind turbine generators is proposed. The effectiveness of the proposed control method is verified by simulation analyses for a severe three-line to ground fault, two-line to ground fault, line to line fault, and one-line to ground fault, respectively, in the multi-machine power system. It has been shown that, if the proposed DFIG control is not available, wind farm composed of induction generators becomes unstable. However, when the DFIG controlled by the proposed method is incorporated in the wind farm, IGs as well as DFIGs in the wind farms become stable. It has also been reported that the proposed control scheme of DFIG can even enhance the transient stability of synchronous generators in the power system up to a certain level. Therefore, it can be concluded that the proposed control method for variable speed wind turbine driving DFIG can be an effective means to enhance the transient stability of the grid connected wind farms.

\section{ACKNOWLEDGMENT}

The authors would like to acknowledge The Petroleum Institute Abu Dhabi, UAE for sponsoring this research work.

\section{REFERENCES}

[1] A.H. Kasem, E. F. El-Saadany, H. H. El-Tamaly, and M. A. A. Wahab, "An improved fault ride-through strategy for doubly fed induction generator-based wind turbines," IET Renewable Power Generation, vol.2, no. 4, pp. 201-214, 2008.

[2] J. A. Suul, M. Molinas and T. Undeland, "STATCOM-based indirect torque control of induction machines during voltage recovery after grid faults," IEEE Trans. on Power Electronics, vol. 25, no. 5, pp. 1240$1250,2010$.

[3] J.Yu, X. Duan, Y. Tang and P. Yuan, "Control scheme studies of voltage source type superconducting magnetic energy storage (SMES) under asymmetrical voltage," IEEE Trans. on Applied Superconductivity, vol.12, no. 1, pp. 750-753, 2002.

[4] S.M. Muyeen, R. Takahashi, M.H. Ali, T. Murata, and J. Tamura, "Transient stability augmentation of power systems including wind farms using ECS," IEEE Tans. on Power Systems, vol. 23, no. 3, pp. 1179-1187, 2008.

[5] A. A. El-Sattar, et-al., "Dynamic response of doubly fed induction generator variable speed wind turbine under fault," Electric Power System Research, pp. 1240-1246, 2008.

[6] I. Erlich, H. Wrede and C. Feltes, "Dynamic behavior of DFIG-based wind turbine during grid faults," IEEJ Trans. Industrial Application, vol. 128 , no. 4 , pp. $396,2008$.

[7] F. Blaabjerg, F. Iov, and K. Ries, "Fuse protection of IGBT modules against explosions," PCIM Conference, China, 2002.

[8] G. O. Cimuca, C. Saudemont, B. Robyns, and M. M. Radulescu, "Control and performance evaluation of a flywheel energy-storage system associated to a variable speed wind generator," IEEE Trans. Ind. Electron., vol. 53, no. 4, pp. 1074-1085, June 2006.

[9] R. Pea, R. Cerdenas, J. Proboste, G. Asher, and J. Clare, "Sensorless control of doubly-fed induction generators using a rotor-current-based MRAS observer," IEEE Trans. Ind. Electron., vol. 55, no. 1, pp. 330339. Jan. 2008.

[10] K.E. Okedu, S. M. Muyeen, R. Takahashi and J. Tamura, "Comparative study between two protection schemes for DFIG-based wind generator," International Conference of Electrical Machines and Systems (ICEMS), Seoul, South Korea, 2010, (online IEEE Explorer)

[11] "PSCAD/EMTDC Manual", Manitoba HVDC research center, 1994.

[12] K.E. Okedu, S. M. Muyeen, R. Takahashi, and J. Tamura, "Stabilization of wind farms by DFIG-based variable speed wind generators," International Conference of Electrical Machines and Systems (ICEMS), Seoul, South Korea, 2010, (online IEEE Explorer)

[13] R. Takahashi, J. Tamura, M. Futami, M. Kimura and K. Idle, "A new control method for wind energy conversion system using double fed synchronous generators," IEEJ Trans. Power and Energy, vol. 126, no. 2, pp. 225-235, 2006 (in Japanese).

[14] R. Takahashi, H. Kinoshita, T. Murata, J. Tamura, M. Sugimasa, A. Komura, M. Futami, M. Ichinose, and K. Ide, "Output power smoothing and hydrogen production by using variable speed wind generators," IEEE Trans. On Ind. Electronics, vol. 57, no. 2, Feb. 2010.

[15] Working Group on Prime Mover and Energy Supply Models for System Dynamic Performance Studies, "Hydraulic turbine and turbine control models for fossil fueled steam units on power system studies," IEEE Trans. Power System, vol. 6, no. 2, pp. 753-761, 1991.

[16] Working Group on Prime Mover and Energy Supply Models for System Dynamic Performance Studies, "Hydraulic turbines and turbine control models for system dynamic studies," IEEE Trans. Power System, vol. 7, no. 1, pp. 167-179.

[17] "IEEE Recommended Practice for Excitation System Models for Power System Stabillity Studies," IEEE STD, 1992; 421.5.

[18] S. Heir, Grid Integration of Wind Energy Conversion Systems, ISBN: 0-471-97143, 1998.

[19] E.ON NETZ GmbH, Grid connection regulation for high and extra high voltage, 2006

[20] M. Yagami, S. Shibata, T. Murata and J. Tamura, "An analysis of superconducting fault current limiter for stabilization of synchronous generator in multi-machine system: A two-machine infinite bus system," IEEJ Trans. PE, vol. 123, no. 2, pp. 133-142, 2003. 